\title{
Birth-date-dependent segregation of the mouse cerebral cortical neurons in reaggregation cultures
}

\author{
Itsuki Ajioka ${ }^{1,2}$ and Kazunori Nakajima ${ }^{1,2,3}$ \\ ${ }^{1}$ Department of Anatomy, Keio University School of Medicine, 35 Shinanomachi, Shinjuku-ku, Tokyo 160-8582, Japan \\ ${ }^{2}$ Department of Molecular Neurobiology, Institute of DNA Medicine, Jikei University School of Medicine, 3-25-8 Nishi-shinbashi, \\ Minato-ku, Tokyo 105-8461, Japan \\ ${ }^{3}$ Precursory Research for Embryonic Science and Technology (PRESTO), Japan Science and Technology Corporation (JST), 4-1-8 \\ Honmachi, Kawaguchi, Saitama 332-0012, Japan
}

Keywords: cortical marginal zone, laminar fate, reelin, ventricular zone

\begin{abstract}
Cerebral cortical neurons form a six-layered structure in which their position depends on their birth date. This developmental process requires the presence of Reelin, which is secreted by Cajal-Retzius cells in the cortical marginal zone (MZ). However, it is still unclear whether the migration from the ventricular zone (VZ) to beneath the $M Z$ is essential for the neurons to segregate into layers. Previous transplantation studies of ferret cerebral cortical neurons suggested that their ultimate laminar fate is, at least to some extent, determined in the VZ but it is unknown how 'laminar fate' eventually positions cells in a specific layer. To explore the segregation properties of mouse cortical cells that have not yet arrived beneath the MZ, embryonic day (E)16 VZ and intermediate zone (IMZ) cells were dissociated and allowed to reaggregate for 1-4 days in vitro. The results suggested that the migrating neurons in the IMZ at E16 preferentially located near the centre of the aggregates, more than did the proliferative cells from the VZ. The birth-date labelling followed by the dissociation-reaggregation culture suggested that the segregation properties of the E16 IMZ was characteristic of the E14-born cells, which were migrating in the IMZ at E16, but they were not general properties of migrating IMZ cells. This birth-date-dependent segregation mechanism was also observed in the Reelin signalling-deficient yotari cells. These findings suggest that cortical neurons acquire a birth-date-dependent segregation mechanism before their somas reach the MZ.
\end{abstract}

\section{Introduction}

The mammalian cerebral cortex consists of six layers of neurons. The neurons are born in the ventricular zone (VZ) of the embryonic cortex and migrate to beneath the cortical marginal zone (MZ), where they form the cortical plate (CP). Because the most of the cortical neurons invariably stop migrating just beneath the $\mathrm{MZ}$ and begin to mature (Tabata \& Nakajima, 2001), the late-born neurons migrate past the early-born neurons (future deep-layer neurons) and come to be aligned in the superficial layers, resulting in the 'inside-out' progression of CP development (Angevine \& Sidman, 1962).

Despite the remarkable recent progress in identification of new molecules that function in the mechanism of neuronal layering, the biological aspects of layer formation in the cerebral cortex are not well understood. One of the major questions to be addressed is whether the neurons need to migrate from the VZ to beneath the MZ to segregate into layers or whether they have already acquired some laminar-fate information before reaching the MZ. Previous transplantation studies of ferret cerebral cortical neurons suggest that their ultimate laminar fate is, at least to some extent, determined in the VZ (McConnell \& Kaznowski, 1991; Frantz \& McConnell, 1996), but it is unknown how 'laminar fate' eventually positions cells in a specific layer.

Previous reaggregation culture studies have suggested that presumptive epidermal and neural cells have preferential cell affinity, and

Correspondence: Dr Kazunori Nakajima, ${ }^{1}$ Department of Anatomy, as above.

E-mail: kazunori@sc.itc.keio.ac.jp

Received 10 March 2005, revised 22 April 2005, accepted 4 May 2005 that it is crucial to final positioning in the early developmental stages (Steinberg, 1970; Townes \& Holtfreter, 1955). This preferential cell affinity was thought to be dependent on the selectivity of cell adhesion (Steinberg \& Takeichi, 1994). Reaggregation culture studies conducted during brain development reveal that the cells dissociated from different brain regions or retina have distinct adhesive properties depending on their regions in vivo (Moscona, 1961; DeLong, 1970; Garber et al., 1980; Hatten \& Francois, 1981; Layer \& Willbold, 1989; Whitesides \& LaMantia, 1995; Gotz et al., 1996; Nakagawa et al., 2003). Krushel \& van der Kooy (1993) have shown that early but not late postmitotic cortical neurons selectively associated in the aggregates. However, because the cortical neurons were dissociated from the whole cerebral cortex in these previous studies it remains to be clarified whether or not the cortical cells acquire their preferential cell affinities before their migration to beneath the MZ.

To determine whether the migration from the $\mathrm{VZ}$ to beneath the MZ is essential for neuronal segregation into layers, in this study we investigated whether migrating neurons have different cell aggregation properties depending on their birth dates, even before they arrive beneath the MZ. We analysed VZ cells and cells from the intermediate zone (IMZ), mainly composed of migrating cells, which normally localized in layer II-IV, from the embryonic day (E) 16 cerebral cortex, which normally localize in layer II-IV, and found that the cells had acquired a birth-date-dependent preferential segregation mechanism in a Reelin-independent manner. This mechanism may contribute to the layer formation in the developing cerebral cortex in concert with other mechanisms such as Reelin signalling. 


\section{Materials and methods}

\section{Electroporation in utero}

Pregnant Institute of Cancer Research (ICR) mice were purchased from Japan SLC (Japan). The expression vector of enhanced green fluorescent protein (EGFP) under the control of the chicken $\beta$-actin promoter and cytomegalovirus enhancer (pCAGGS-EGFP vector) was injected into the lateral ventricle of E13.5 mouse embryos. The embryos were electroporated as described previously (Tabata \& Nakajima, 2001). At E15.5, E18.5 or postnatal day (P)14, the brains of the transfected mice were fixed with $4 \%$ paraformaldehyde and cryosectioned. For transfection, animals were anaesthetized with nembutal. For fixation, animals were anaesthetized with diethyl ether, and then killed by perfusion fixation.

\section{Preparation of the VZ, IMZ and CP cells}

The cerebral hemispheres were dissected out from E16 and E14 mice, and the anterior one-third and the posterior one-third of specimens were removed. After removing the meninges, the VZ, IMZ, and CP of the E16 specimens and the VZ-IMZ and CP of the E14 specimens were manually dissected from the lateral cortices under a dissecting microscope as shown in Fig. 5A, and incubated with $0.1 \%$ trypsin in $\mathrm{Ca}^{2+}$ - and $\mathrm{Mg}^{2+}$-free phosphate-buffered saline (PBS) for $10 \mathrm{~min}$ at $37^{\circ} \mathrm{C}$. In this paper, 'VZ' actually also contains the subventricular zone (SVZ), because it was technically difficult to dissect between the VZ and SVZ. In the experiments investigating $\mathrm{Ca}^{2+}$ dependency, the specimens were treated with PBS containing $0.01 \%$ trypsin and $10 \mathrm{mM} \mathrm{Ca}^{2+}$ (TC treatment) or $0.0005 \%$ trypsin in $1 \mathrm{mM}$ ethylenediamine tetraacetic acid (EDTA) (LTE treatment) for $30 \mathrm{~min}$ at $37{ }^{\circ} \mathrm{C}$, as described by Matsunami \& Takeichi (1995). We confirmed that the cells were dissociated into single cells under a haemocytometer. Cell Tracker Green CMFDA and Orange CMTMR (Molecular Probes, OR, USA) were used for the fluorescent labelling according to the manufacturer's instructions. For the experiment using yotari mice, heterozygotes were mated with each other and their offspring's genotypes were determined by PCR (Kojima et al., 2000). In the culture experiments, homozygous cells and a mixture of wild-type and heterozygous cells were used. All procedures conformed to the guidelines on animal experiments of the Japan Neuroscience Society and our institution.

\section{Long-term aggregation culture}

Long-term aggregation culture was performed by a modification of the protocol in the previous report (Ogawa et al., 1995). Briefly, $3.0 \times 10^{5}$ cells in Dulbecco's modified Eagle's medium with nutrient mixture F-12 (DMEM-F12) medium (Sigma, MO, USA) supplemented with $10 \%$ fetal calf serum were incubated with rotation (5 r.p.m.) under $5 \% \quad \mathrm{CO}_{2}$ conditions. At the end of 1-4 days in vitro (div), the aggregates were fixed in $4 \%$ paraformaldehyde and cryosectioned. Nissl staining was performed with Cresyl Violet. Some cells formed not spherical aggregates but rather flat or rugged aggregates. In this study, only spherical aggregates were analysed.

\section{Immunostaining}

Cryosections were preincubated with $5 \%$ bovine serum albumin in PBS and incubated with mouse anti-5'-bromodeoxyuridine (BrdU;
Becton Dickinson, CA, USA), mouse anti- $\beta$ III-tubulin (TuJ1; Berkeley Antibody Company; CA, USA), mouse antimicrotubule-associated protein 2 (MAP2; ICN, OH, USA), rabbit antiglial fibrillary acidic protein (GFAP; DAKO, CA, USA), rabbit anti-calbindin (Swant; Switzerland), mouse anti-proliferating cell nuclear antigen (PCNA) (PC10; Santa Cruz; CA, USA), mouse anti-Otx1 (Weimann et al., 1999) or rabbit anti-EphA3 (C-19; Santa Cruz) for $16 \mathrm{~h}$ at $4{ }^{\circ} \mathrm{C}$. For BrdU staining, cryosections were pretreated with $2 \mathrm{~N} \mathrm{HCl}$ at $37{ }^{\circ} \mathrm{C}$ for $30 \mathrm{~min}$. The primary antibodies were visualized with Cy5-labelled antimouse immunoglobulin $\mathrm{G}$ (IgG) or FITC-labelled antirabbit IgG. Nuclei were counterstained with $1 \mu \mathrm{g} / \mathrm{mL}$ propidium iodide. Fluorescence images were obtained with a confocal microscope (Zeiss LSM510; Germany).

\section{Western blotting}

The dissected VZ, IMZ and CP tissues were dissolved in lysis buffer (Tris, $20 \mathrm{~mm}$, pH 7.4; NaCl, 150 mM, EDTA, 1 mM, NP-40, 1\%; and phenylmethanesulphonyl fluoride, $1 \mathrm{mM}$ ) and protease inhibitor (complete, EDTA-free; Roche, Germany), and the samples were centrifuged at $20000 \mathrm{~g}$ for $20 \mathrm{~min}$. The supernatants were dissolved in SDS loading buffer and subjected to SDS-PAGE on $10 \%$ polyacrylamide gel. Proteins were then electroblotted on to polyvinylidene fluoride membranes in transfer buffer for $1.5 \mathrm{~h}$ at $100 \mathrm{~V}$. The filters were incubated with the first antibodies for $2 \mathrm{~h}$ after blocking with 5\% skimmed milk, and then with peroxidase-labelled second antibodies for $1.5 \mathrm{~h}$. The bands were detected using a chemiluminescent blotting substrate (Roche).

\section{Short-term aggregation culture}

For short-term aggregation culture, $7.5 \times 10^{5}$ cells isolated from the VZ, IMZ or CP were spread on a SIGMACOTE (Sigma, MO, USA)coated 24-well polystyrene plate (Falcon, NJ, USA) in DMEM-F12 supplemented with $0.5 \%$ bovine serum albumin, and cultured at $37{ }^{\circ} \mathrm{C}$ with rotation ( 80 r.p.m.). At the end of $1 \mathrm{~h}$ in vitro (hiv), the cell aggregates were transferred to CELL-TAK (BD Bioscience, MA, USA)-coated culture slides (Falcon) and fixed with 1\% glutaraldehyde for $2 \mathrm{~min}$. The aggregates were examined with a phase-contrast microscope (IX81; Olympus; Japan) and photographed with a CCD camera (Hamamatsu C5810; Japan).

\section{BrdU labelling experiment}

For in vitro BrdU labelling, BrdU (Sigma) $3 \mu \mathrm{g} / \mathrm{mL}$ was added to the aggregates and they were fixed at 96 hiv and cryosectioned. For in vivo BrdU labelling, E13, E14 or E15.5 mice were intraperitoneally injected with BrdU, $50 \mu \mathrm{g} / \mathrm{g}$ body weight, twice at an interval of $4 \mathrm{~h}$ (Takahashi et al., 1996).

\section{Statistical analysis}

To determine the distribution of the cells, fluorescence images of the aggregates were divided into five areas each with Canvas software (Deneba Systems, FL, USA), and the cells in each area were counted with NIH image software. The results are shown as means $\pm \mathrm{SD}$. Differences between groups were analysed for statistical significance by one-way ANOVA followed by a Student-Newman-Keuls test. A $P$ value $<0.05$ was considered evidence of a statistically significant difference. 


\section{Results}

\section{Birth-date-dependent alignment of migrating neurons in the developing cerebral cortex in vivo}

To examine the migration profile of the cortical neurons in vivo, we used the in utero electroporation system (Tabata \& Nakajima, 2001; Tabata \& Nakajima, 2002; Tabata \& Nakajima, 2003). Using this system, the pyramidal neurons undergoing their final mitosis in the VZ can be visualized for a long time by transfection of a reporter gene (Tabata \& Nakajima, 2001; Tabata \& Nakajima, 2002; Tabata \& Nakajima, 2003). Unlike retrovirus transfection, the labelling of the dividing cell population in the VZ became weaker over time, probably because of dilution of the marker by cell division. We injected the EGFP-expressing plasmid vector under the control of the chicken $\beta$-actin promoter and cytomegalovirus enhancer (CAG) into the lateral ventricle of the mouse embryos at E13.5 and fixed the embryos at E15.5, E18.5 or P14. By E15.5, the E13.5-transfected cells had migrated out of the VZ and accumulated in the IMZ and SVZ (Fig. 1A). By E18.5, most of the migrating cells had passed the earlyborn CP cells, which were observed in the CP as EGFP-negative cells, and reached beneath the MZ (Fig. 1C). Interestingly, although the cells seemed to migrate individually through the CP (arrowheads in Fig. 1A and $\mathrm{C}$ ), they accumulated beneath the $\mathrm{MZ}$ when the migration was finally complete (Fig. 1C), suggesting that the cells probably start to form new intercellular relationships with adjacent cells once their migration is complete. At P14, most of the E13.5-transfected cells were aligned around layer IV (Fig. 1E). These results indicate that cortical neurons born in embryos of the same stage preferentially localize around a specific layer in the $\mathrm{CP}$ after migration.

\section{Segregation of early-born neurons and late-born neurons in the long-term reaggregation culture}

To understand the mechanism of this birth-date-dependent positioning, we then addressed the question of whether the migration from the VZ to beneath the MZ was essential for this neuronal segregation into layers. We utilized the reaggregation culture system to directly investigate the cortical neurons. To assess the aggregation properties of VZ and IMZ cells, we dissected out and dissociated the VZ and IMZ cells from mouse E16 lateral cortex and cultured the whole population for 3 days in the rotation culture system ('long-term reaggregation'). For technical reasons, the 'VZ' population in the culture experiments described in this paper contained not only the VZ but also the SVZ, which contains the glial progenitors and at least the future upper layer neurons (Privat, 1975; Tarabykin et al., 2001). Because the majority of the IMZ cells and VZ cells at E15.5 were future layer IV cells (Fig. 1) and layers II and III cells, respectively, the aggregation properties of the E16 VZ and IMZ cells are thought to reflect the properties of the future layer II-IV cells.

FIG. 1. Preferential cell alignment of E13.5-born cells into a specific layer in the developing cerebral cortex in vivo. The EGFP-expressing plasmid vector under the control of CAG was injected into the lateral ventricle of E13.5 mouse embryos (green). At (A,B) E15.5, (C and D) E18.5, or (E and F) P14, the brains were fixed and cryosectioned. The sections were counterstained with PI (violet). (A) At E15.5, E13.5-transfected cells migrated from the VZ to the IMZ and accumulated in the IMZ. (C) At E18.5, most of the migrating cells had passed the early-born CP cells, which were negative for EGFP, and accumulated beneath the MZ. The diffuse fluorescence in the MZ indicates the dendritic structures of the EGFP-positive cells beneath the MZ, which also extended EGFP-positive axons into the IMZ. The arrowheads in $\mathrm{A}$ and $\mathrm{C}$ indicate the migrating cells in the CP. (E) At P14, E13.5-transfected cells were mainly aligned in layer IV. Ch, choroid plexus. Scale bar, $100 \mu \mathrm{m}$.
First, we examined the general structure of the aggregates. Immunostaining for TuJ1, a marker for both immature and mature neurons, and for GFAP, a glial marker, revealed that most cells in the aggregates were neurons (Fig. 2A, B, E and F). In contrast to the aggregates cultured from E16 ('E16 aggregates'), GFAP was strongly

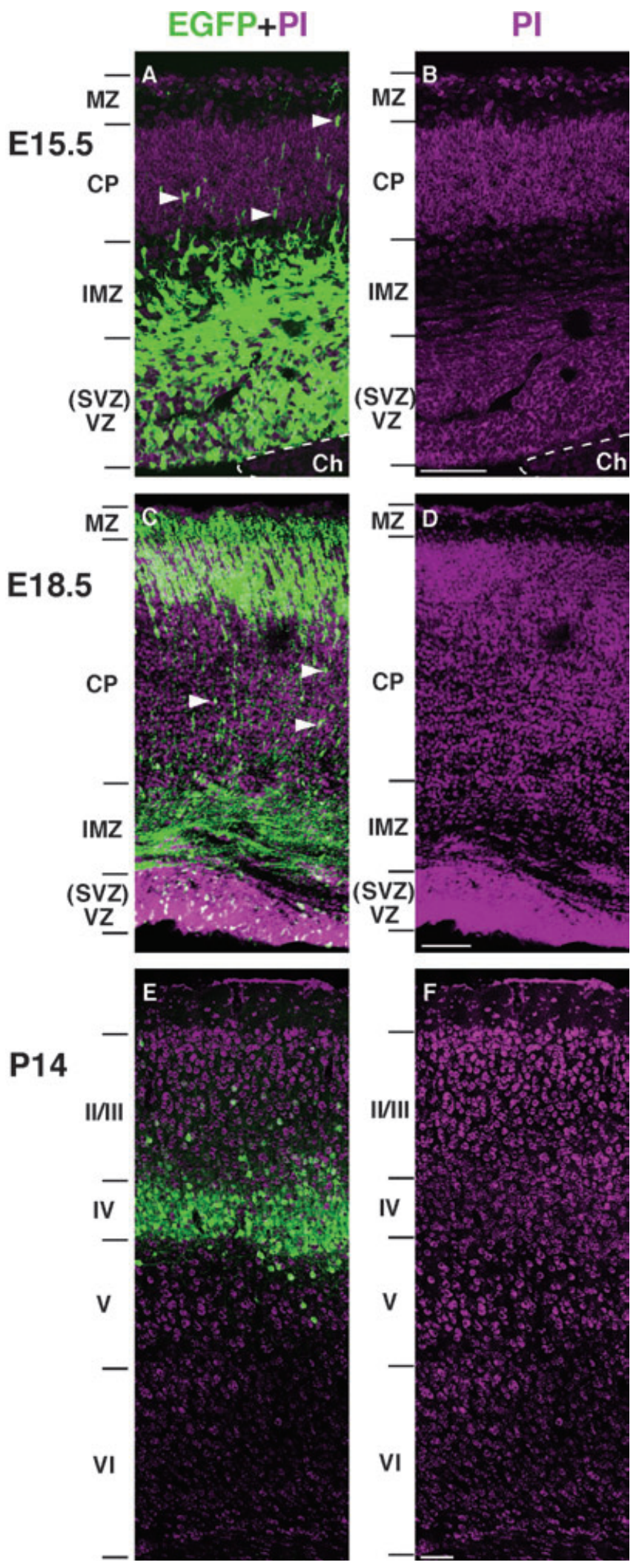



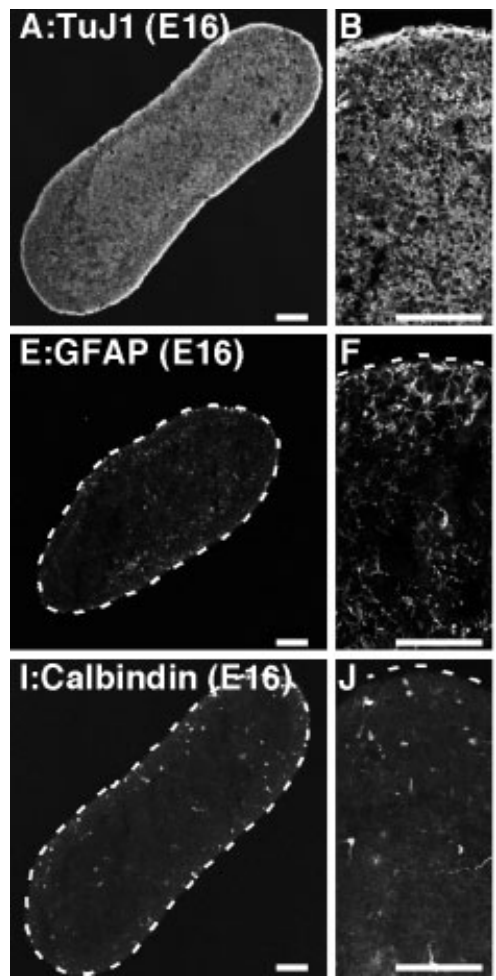

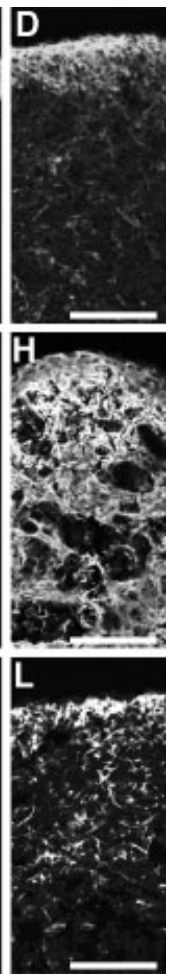

FIG. 2. Characterizations of long-term VZ and IMZ aggregates. Aggregates of (A-F, I-L) E16 VZ and IMZ cells after 3 div or (G and H) P0 VZ and IMZ cells. (A and B) TuJ1, (C and D) MAP2, (E-H) GFAP, (I,J) calbindin and (K and L) nestin staining. Note that (A-F, I-L) the dissociated E16 VZ and IMZ cells as a whole had the ability to align in a certain reproducible pattern even without having migrated to beneath the $\mathrm{MZ}$, and $(\mathrm{K}$ and $\mathrm{L})$ the proliferative cells were localized near the surface of the E16 VZ and IMZ aggregates. Scale bars, $50 \mu \mathrm{m}$.

stained in the aggregates cultured from P0 (Fig. $2 \mathrm{G}$ and $\mathrm{H}$ ), suggesting that the majority of the glial cells appeared postnatally. Antibody against MAP2, which preferentially stains young mature neurons, strongly labelled the cells near the surface of the E16 aggregates (Fig. 2C and D). Calbindin, which is a marker of some populations of interneurons (Anderson et al., 1997), was expressed in a few scattered cells in the E16 aggregates (Fig. 2I and J). To examine the localization of the neural precursor cells we used an antibody against nestin and found that this antibody preferentially stained the surface side of the aggregates, suggesting that the proliferative cells were also localized near the surface of the E16 VZ and IMZ aggregates (Fig. 2K and L). These results were reproducible and consistent among different aggregates, suggesting that the dissociated E16 VZ and IMZ cells as a whole had the ability to align in a certain reproducible pattern even without having migrated to beneath the MZ. To identify the localization of newly appearing cells during culture and the cells that have already completed their final mitosis before the culture, we used a fluorescent probe that is diluted by cell division. The E16 VZ and IMZ cells were labelled with Cell Tracker Green or Orange fluorescent probe just after dissociation, and cultured. Although all cells were strongly stained with Cell Tracker at the beginning of the culture, weakly stained cells, which presumably represented newly appearing cells during culture, appeared over time (Fig. 3A, 48 hiv). Interestingly, the strongly labelled cells that would have already completed their final mitosis before culture gradually segregated from the weakly labelled cells, and came to rest near the centre of the aggregates in a time-dependent manner [Fig. 3A (72 and 96 hiv) and B]. Both the Cell Tracker Green stain and Orange stain yielded similar results, and the results suggested that the early-born neurons (strongly labelled cells) aggregated preferentially and more strongly with each other than with the late-born neurons (weakly stained cells). To identify the differen- tial localization of the cells within the aggregates depending on the time of their final division, we injected $\mathrm{BrdU} 48 \mathrm{~h}$ before dissociation or added BrdU to the culture medium for the first $24(0-24 \mathrm{~h})$ or last 24 (72-96 h) hours during culture, and fixed the aggregates at $96 \mathrm{~h}$ in vitro (Fig. 4). The BrdU-positive cells that were labelled before the dissociation were localized near the centre of the aggregates (Fig. 4A and D); on the other hand, the BrdU-positive cells that were labelled during the culture were localized near the surface of the aggregates (Fig. 4B-D). We did not observe any significant increase in cell death following the BrdU injection, as revealed by terminal deoxynucleotidyl transferase-mediated deoxyuridine triphosphate-biotin nick-end labelling (TUNEL) assay (data not shown). The results were consistent with those shown in Fig. 3. In view of the report showing that cell segregation is dependent on the level of expression of cell adhesion proteins (Steinberg \& Takeichi, 1994), these finding suggested that neurons derived from the E16 VZ and IMZ segregated according to their time of birth, and that at this stage early-born neurons aggregated with each other more strongly than with late-born neurons.

\section{E16 IMZ neurons tended to localize near the centre of the aggregates}

The mixture of E16 VZ cells and IMZ cells was used in the experiments shown in Figs 3 and 4. Because most cells in the IMZ were migrating neurons that had already completed their final mitosis in the VZ, the strongly labelled cells after long-term culture shown in Fig. 3 or the BrdU-positive cells that were labelled before the dissociation shown in Fig. 4 are likely to be mainly IMZ cells in the E16 cortex, and the weakly stained cells (Fig. 3) or BrdU-positive cells that were labelled during 
A

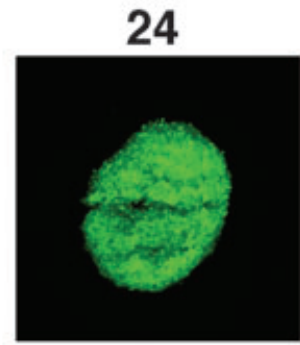

48
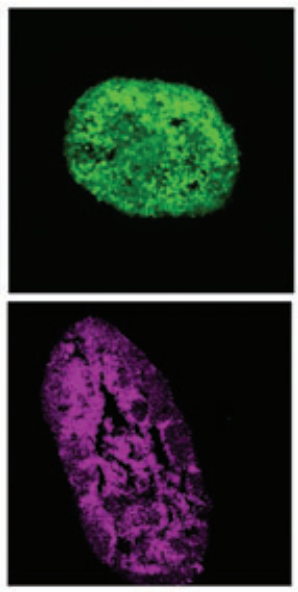

72
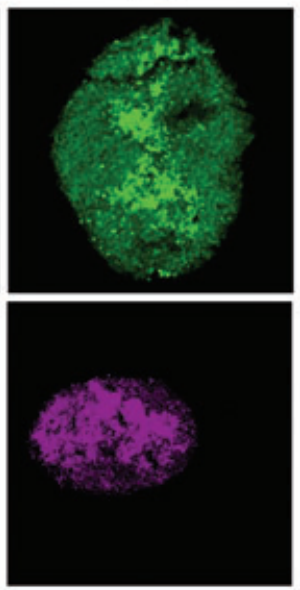

96 (hiv)

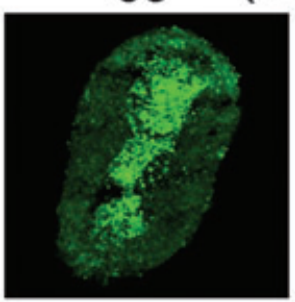

\section{CellTracker}

Green

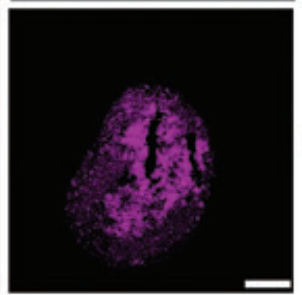

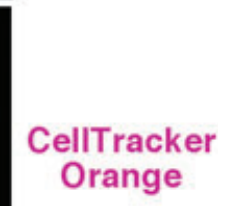

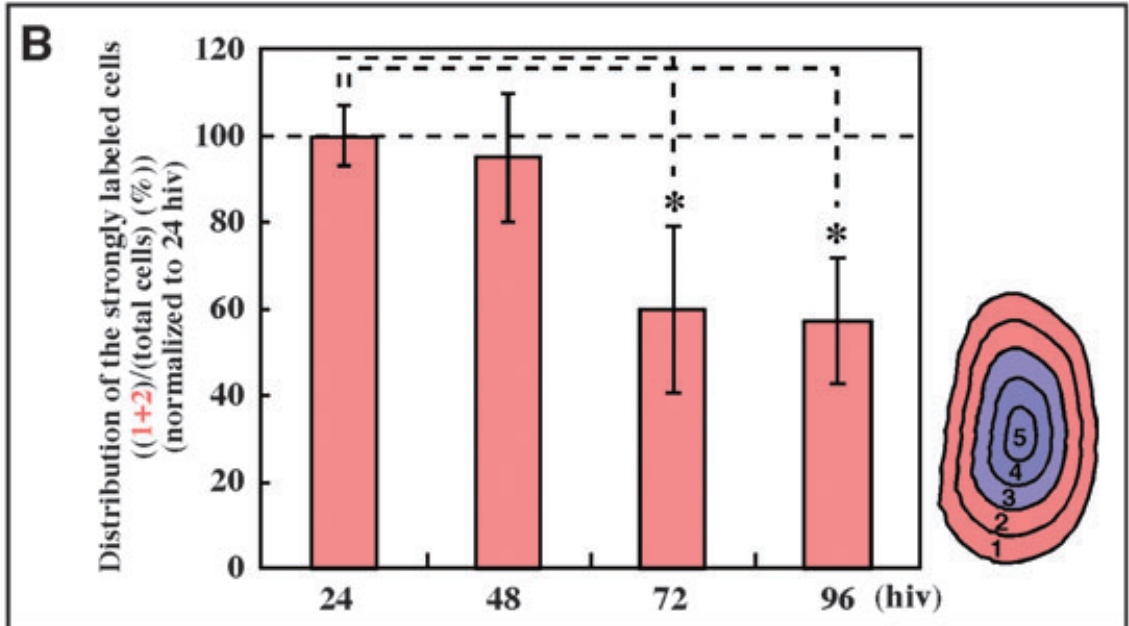

FIG. 3. Cell segregation between the early-born cells and the late-born cells in the reaggregation culture. E16 VZ and IMZ cells were labelled with Cell Tracker Green or Cell Tracker Orange and rotation-cultured (5 r.p.m.). (A) Fluorescence images of the cryosections of aggregates that were cultured for $24,48,72$ and 96 hiv. Note that weakly stained cells gradually appeared and segregated from the strongly labelled cells in a time-dependent manner. (B) The distribution of the strongly fluorescence-labelled cells within the aggregates was quantitatively evaluated by counting the cells in each of five areas that were created by dividing the cross-sections of the aggregates. The ratios of the cell numbers in areas $1+2$ to those in all the areas were calculated and normalized to the aggregates of 24 hiv. $* P<0.05$. Scale bar, $100 \mu \mathrm{m}$.

culture (Fig. 4) were most probably derived from the VZ. To directly investigate whether IMZ cells and VZ cells have different aggregation properties, we dissected out and dissociated the VZ cells and IMZ cells from E16 cortex separately (Fig. 5A), and labelled them each with a different fluorescent probe. To estimate the purity of the manually dissected VZ cells or IMZ cells, we examined the marker expressions in the manually dissected VZ or IMZ tissues by Western blotting. We used antibodies against PCNA as the VZ marker, against EphA3 as the IMZ marker (Kudo et al., 2005) and against TuJ1 for all the layers (Fig. 5CE). The results showed that the manually dissected VZ tissues and IMZ tissues were successfully separated (Fig. 5B). We then mixed them together and cocultured them. After 3 div, the IMZ cells were preferentially located near the centre of the aggregates (Fig. 5F-H and L). By contrast, when the VZ cells were divided into two populations, one was stained with green fluorescence and the other with orange fluorescence, and cultured together, both the green-labelled VZ cells and the orange-labelled VZ cells were dispersed throughout the aggregates (Fig. 5I-L), suggesting that the differential localization of the green-labelled IMZ cells and the orange-labelled VZ cells was not attributable to the difference in fluorescent probes. Thus, the E16 IMZ cells tended to localize near the centre of the aggregates, suggesting that the postmitotic neurons in the E16 IMZ preferentially aggregate with each other. We also attempted long-term reaggregation culture of the E16 IMZ cells alone; these cells formed rugged aggregates, but no spherical aggregates (data not shown), suggesting the possibility that the VZ cells which contained the radial glial cells and neural precursor cells were required for the formation of spherical aggregates as previously demonstrated for retinal reaggregates (Willbold et al., 1995).

\section{E16 IMZ neurons preferentially adhered to each other by a $\mathrm{Ca}^{2+}$-dependent cell adhesion mechanism}

Other aspects besides the cell adhesion properties, such as cell division, migration and differentiation, may also contribute to the final pattern of cell distribution in the long-term reaggregation culture system. We therefore performed a short-term aggregation assay to investigate the adhesion properties of the IMZ cells (Takeichi, 1977) because short-term aggregation assay is thought to directly reflect the expression and regulation of signalling molecules on the cell surface. 

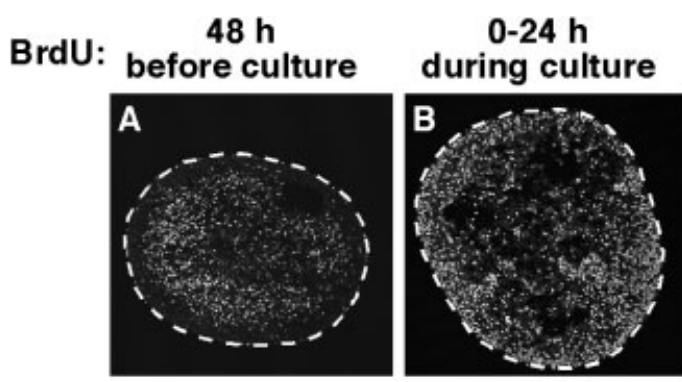

72-96 h during culture

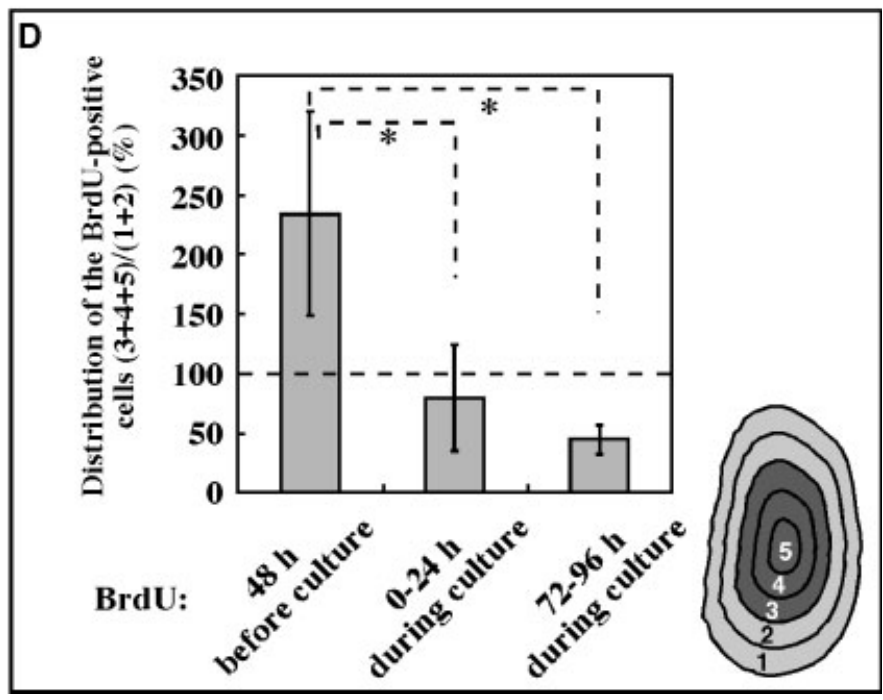

FIG. 4. Localization of the cells that are born before and after dissociation in the E16 VZ and IMZ aggregates. E16 VZ and IMZ cells labelled with BrdU were rotation-cultured for $96 \mathrm{~h}$ (5 r.p.m.). The cells were labelled with BrdU (A) $48 \mathrm{~h}$ before culture, or (B) 0-24 or (C) 72-96 hours during culture. Cryosections of the aggregates were stained with anti-BrdU antibody. (D) Statistical analysis was performed by dividing the fluorescence images of the aggregates into five areas $(n=5) ;{ }^{*} P<0.05$. Scale bar, $100 \mu \mathrm{m}$.

When dissociated cells from the E16 VZ, IMZ and CP were cultured separately in a rotating plate for $1 \mathrm{~h}$, the IMZ cells showed a stronger tendency to form large aggregates than did the VZ and CP cells. These findings suggest that the postmitotic migrating neurons in the E16 IMZ have stronger adhesion properties than the $\mathrm{CP}$ or $\mathrm{VZ}$ cells (Fig. 6A and B).

To identify the adhesion mechanism that mediates the adhesive properties of the E16 IMZ cells, we investigated the $\mathrm{Ca}^{2+}$ dependency of the cell adhesion. Cell adhesion mechanisms are classified into $\mathrm{Ca}^{2+}$-dependent and $\mathrm{Ca}^{2+}$-independent, and exposure to a low concentration of trypsin in the presence of EDTA ('LTE treatment') interferes with the $\mathrm{Ca}^{2+}$-dependent cell adhesion because the $\mathrm{Ca}^{2+}$-dependent adhesion molecules are highly sensitive to trypsin in the absence of $\mathrm{Ca}^{2+}$ (Matsunami \& Takeichi, 1995). In the presence of $\mathrm{Ca}^{2+}$, however, the $\mathrm{Ca}^{2+}$-dependent molecules become resistant to trypsin, allowing selective digestion of the $\mathrm{Ca}^{2+}$-independent molecules ('TC treatment'). The preferential cell adhesion of the E16 IMZ cells in the short term aggregation culture was not inhibited by TC treatment but was inhibited by LTE treatment (Fig. 6C and D). In addition, it was not inhibited by the RGD peptide, which suppresses integrin-mediated cell adhesion (data not shown). These results suggest that the preferential adhesion of E16 IMZ cells is mediated by the $\mathrm{Ca}^{2+}$-dependent cell adhesion mechanism.

\section{Birth-date-dependent segregation of cerebral cortical neurons}

The next question to be addressed was whether the preferential cell segregation of the E16 IMZ cells reflected the properties of migrating
IMZ cells in general (IMZ-specific) or is specific only to the IMZ cells at E16 (stage-specific). To answer this question, we compared the distribution pattern of cortical cells in reaggregation culture at other stages of embryonic development. Neurons that were born at a certain stage of development ('birth-date') were labelled with BrdU as a marker. As shown in Fig. 7A and B, the cells that were strongly labelled with BrdU at E15.5 were located mainly in the VZ at E16, whereas many cells that were labelled at E14 were already migrating in the IMZ at E16. When VZ and IMZ cells from E16 cerebral cortex were cultured in the long-term reaggregation system, the E14-labelled cells were located near the centre of the aggregates (Fig. 7E and I) whereas the E15.5-labelled cells were dispersed throughout the aggregates (Fig. 7F and I). The reason that the BrdU-labelled cells in the $\mathrm{VZ}$ were dissociated 0.5 days after BrdU injection agreed with the report that the laminar fate was determined in the G2-M phase of the final mitosis (McConnell \& Kaznowski, 1991). These findings were consistent with the result of the experiments shown in Fig. 5. To determine the pattern of distribution of IMZ cells from a different stage of development, we then labelled neurons with BrdU at E13 or E14 and started culturing at E14.5. When the VZ and IMZ cells from E14.5 cortex were cultured in the long-term reaggregation system, the E14-labelled cells were located near the centre of the aggregates (Fig. 7H and I), although most of them were still in the $\mathrm{VZ}$ in vivo at E14.5 (Fig. 7D); however, the E13-labelled cells, many of which had already migrated into the IMZ at E14.5 in vivo (Fig. 7C), were preferentially located near the surface of the aggregates (Fig. 7G and I). The reason that the IMZ cells were BrdU-labelled at E13 (1.5 days before dissociation) but not at E12.5 (2.0 days before the dissociation, 

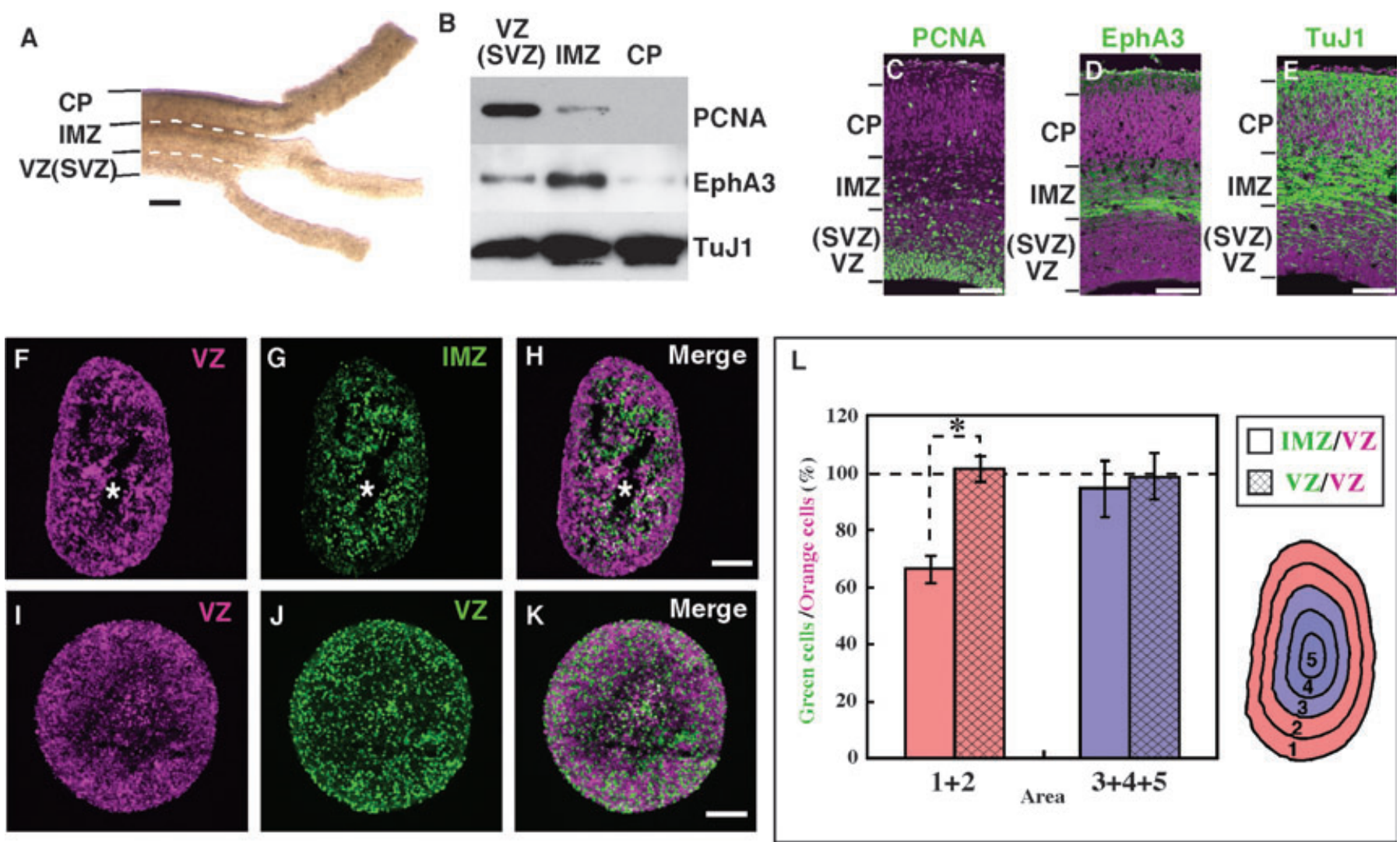

FIG. 5. The E16 IMZ cells were located near the centre of the aggregate. (A) The E16 VZ, IMZ and CP tissues were dissected manually under a stereoscopic microscope. (B) The lysates of the dissected VZ, IMZ and CP tissues were subjected to Western blotting for PCNA, EphA3 and TuJ1. (C-E) The E16 cerebral cortex was immunostained with PCNA, EphA3 or TuJ1 (green) and counterstained with propidium iodide (violet). (F-H) Dissociated E16 VZ cells were labelled with Cell Tracker Orange and dissociated E16 IMZ cells were labelled with Cell Tracker Green. (I-K) Dissociated E16 VZ cells were divided into two groups and labelled with Cell Tracker Orange and Cell Tracker Green, respectively. These cells were rotation-cultured (5 r.p.m.) for 3 days. (F-K) Fluorescence images of the aggregates. The asterisks indicate artificial defects in the cryosections. (L) The distribution of the green-labelled cells within the aggregates was quantitatively evaluated by counting the cells in each of the five areas created by dividing the cross sections of the aggregates, and the ratio of green-labelled cells : orange-labelled cells was calculated. In areas $1+2$, near the surface of the aggregates of the mixed culture of IMZ and VZ cells, the ratio of the number of green-labelled IMZ cells to the number of orange-labelled VZ cells was $66.3 \pm 4.8 \%(n=5)$. By contrast, in area 3 and areas $4+5$, near the centre of the aggregates, the ratios were $96.6 \pm 8.4$ and $90.3 \pm 24.8 \%$, respectively $(n=5)$. There were no significant differences among the areas in the mixed culture of VZ and VZ cells. ${ }^{*} P<0.05$. Scale bars, $200 \mu \mathrm{m}(\mathrm{A}), 100 \mu \mathrm{m}(\mathrm{C}-\mathrm{K})$.

which was adopted for the above-mentioned E16 culture) was attributed to the length of the cell cycle being shorter at this stage than at later stages (Takahashi et al., 1996). The distribution of the BrdU-labelled cells was quantified and analysed by calculating the ratios of the number of BrdU-labelled cells near the centre of the aggregates (areas 3-5) to that near the surface of the aggregates (areas 1-2) (Fig. 7I). The results suggested that E14-labelled cells tended to be localized near the centre of the aggregates irrespective of their initial location in vivo (VZ or IMZ) at the time of dissociation for culture. The results also imply that the preferential localization of the E13-labelled cells (which had undergone their final mitotic cycle before the start of their culturing) near the surface of the aggregates did not simply indicate that the mitotic cells tended to localize near the surface of the aggregates (Figs 3D, and 4B and C). These results imply that neurons born in the VZ at E14 (and migrating through the IMZ at E16) have already acquired or are at least destined to acquire birth-date-dependent cell segregation properties even before their migrating to beneath the MZ. E14-labelled cells are known to ultimately be preferentially distributed in layer IV, while many of the E13-labelled cells were located in layers V and VI and the E15.5labelled cells were located in layers II and III (Takahashi et al., 1999). Indeed, Otx1, which is a marker for layer V and VI neurons (Frantz et al., 1994b), was preferentially expressed near the surface of the aggregates that had been cultured from E14.5 (Fig. 7J), similar to the localization of the E13-labelled cells (Fig. 7G). We also examined the expression pattern of retinoid-related orphan receptor $\beta$ $(\operatorname{ROR} \beta)$ mRNA, which is known to be expressed in layer IV neurons (Park et al., 1997), in the aggregates cultured from E14.5 and E16. However, we could not detect any signals (data not shown), perhaps because ROR $\beta$ is known to be expressed after neurons mature in vivo. These findings and the results of the experiments describe above imply that at least the migrating neurons in the cortex destined to populate the future layer IV and adjacent layers (layers II and III and layer V) may have birth-date-dependent different segregation properties.

\section{Birth-date-dependent segregation mechanism was independent of Reelin signalling}

The well-organized cortical developmental events are orchestrated by the Reelin cascade. Reelin is a huge extracellular matrix protein secreted by Cajal-Retzius neurons in the MZ (D'Arcangelo et al., 1995; Hirotsune et al., 1995; Ogawa et al., 1995; Nakajima et al., 1997), and is thought to control the final positioning of migrating neurons. The spontaneous Reelin-deficient mouse, reeler (Falconer, 

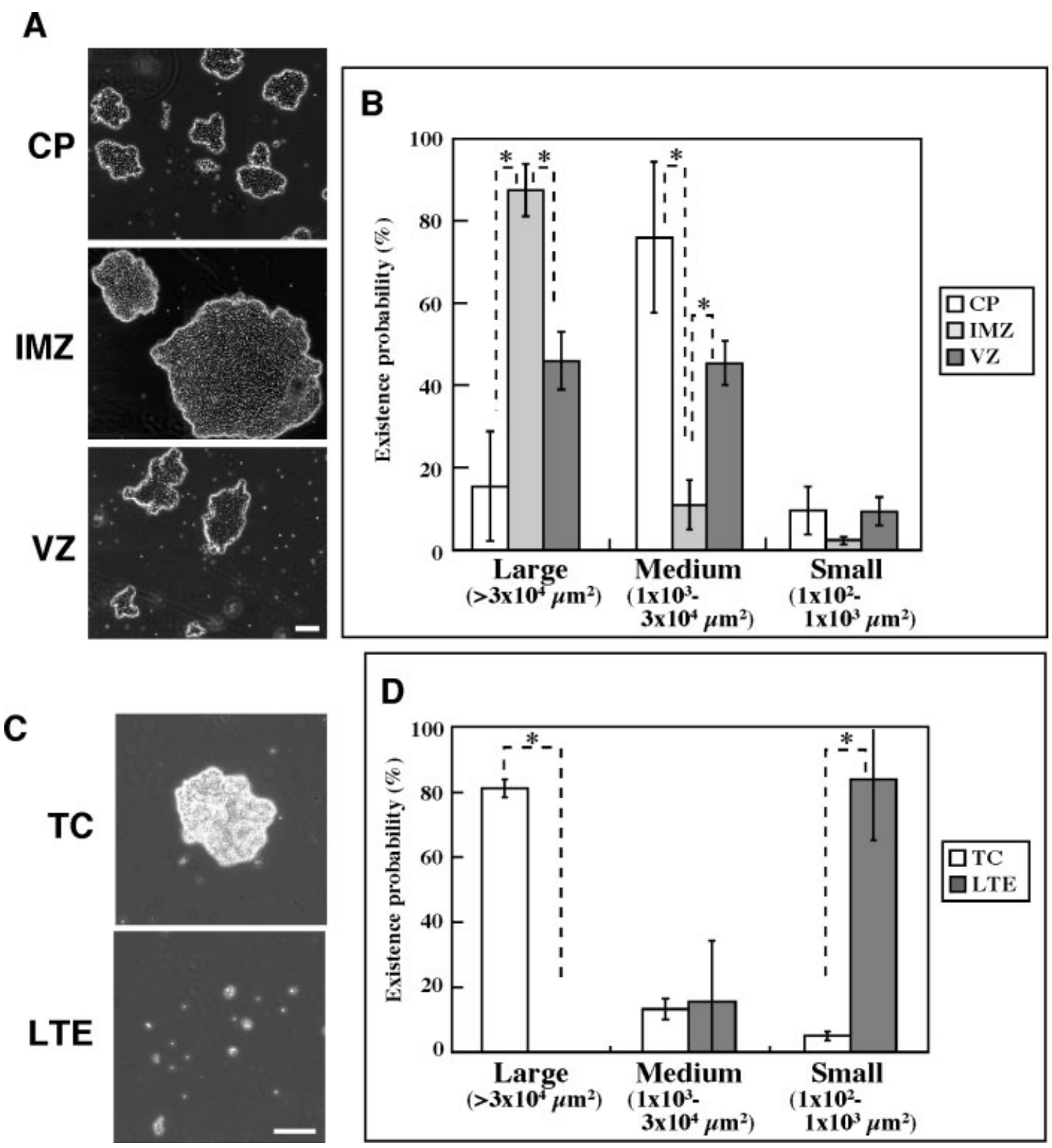

FIG. 6. E16 IMZ neurons had strong adhesive properties. (A and B) The E16 VZ, IMZ and CP cells were dissected separately and dissociated with $0.01 \%$ trypsin in PBS. The cells were then rotation-cultured (80 r.p.m.) for $1 \mathrm{~h}$. (A) Phase-contrast images of the aggregates. Note that the IMZ cells formed larger aggregates than the $\mathrm{VZ}$ and $\mathrm{CP}$ cells. (B) The aggregates were classified into three groups according to their sizes. It was determined that $45.6 \pm 6.9 \%$ of the $\mathrm{VZ}$ cell aggregates, $86.8 \pm 6.3 \%$ of the IMZ cell aggregates and $15.2 \pm 13.3 \%$ of the CP cell aggregates were classified into the large-aggregate group $(n=3$ independent experiments). On the other hand, $45.1 \pm 5.3 \%$ of the VZ cell aggregates, $10.9 \pm 6.0 \%$ of the IMZ cell aggregates and $75.3 \pm 18.1 \%$ of the CP cell aggregates were classified into the medium-aggregate group, and $9.34 \pm 3.51 \%$ of the VZ cell aggregates, $2.27 \pm 0.88 \%$ of the IMZ cell aggregates and $9.42 \pm 5.70 \%$ of the CP cell aggregates were classified into the small-aggregate group. (C and D) After the cells were dissociated, the E16 IMZ cells were exposed to PBS containing $0.01 \%$ trypsin and Ca ${ }^{2+}$ (TC treatment) or $0.0005 \%$ trypsin in $1 \mathrm{~mm}$ EDTA (LTE treatment). (C) Phase-contrast images of the aggregates. (D) The aggregates were classified into three groups as shown in B. Scale bars, $100 \mu \mathrm{m}$. ${ }^{*} P<0.05$.

1951), shows severe abnormalities of neuronal positioning in the cerebral cortex (Caviness \& Sidman, 1973). To investigate whether the birth-date-dependent segregation mechanism is independent of Reelin signalling, we then used the VZ and IMZ cells of yotari mice, in which the Reelin signal is not transduced due to a deficiency of the intracellular adaptor protein Disabled homologue 1 (Dab1) (Sheldon et al., 1997; Yoneshima et al., 1997; Kojima et al., 2000). As shown in Fig. 8, the E14-labelled cells of homozygous yotari mice tended to be located near the centre of the aggregates, similar to the E14-labelled cells of the wild type and heterozygous mice (see also Fig. 7E and I), suggesting that the birth-date-dependent cell segregation mechanism is independent of Reelin signalling.

\section{Discussion}

In this study we investigated whether migration of cortical neurons from the $\mathrm{VZ}$ to beneath the $\mathrm{MZ}$ is a requirement for them to segregate into different layers. Transplantation studies of ferret cerebral cortical neurons have suggested that the cellular environment plays a critical role in layer formation (McConnell \& Kaznowski, 1991). In the ferret, 
E14

E16

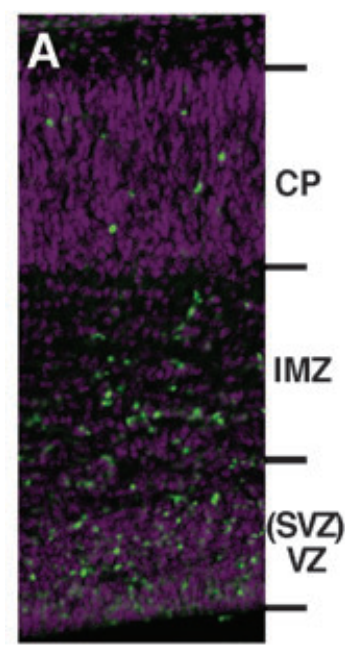

E14

E16

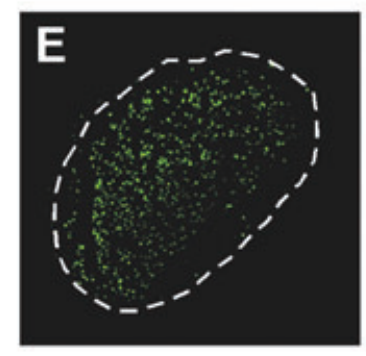

E15.5

E16

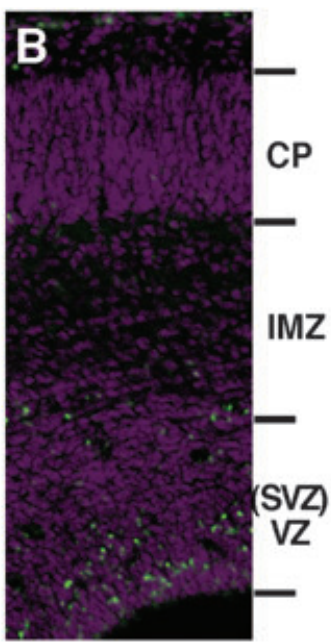

E15.5 E16

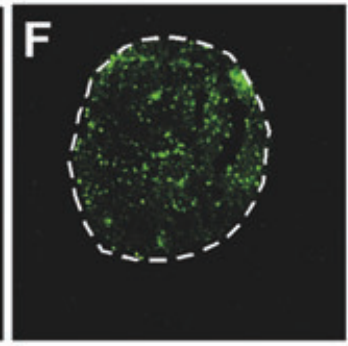

E14.5

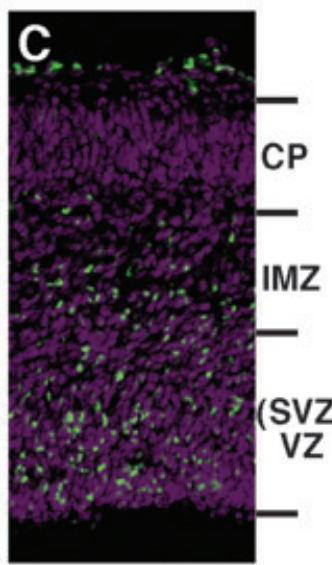

E13

E14.5

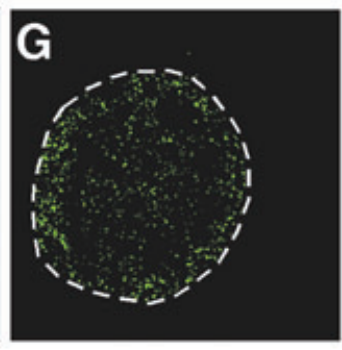

E14

E14.5

\section{BrdU}

Fix 

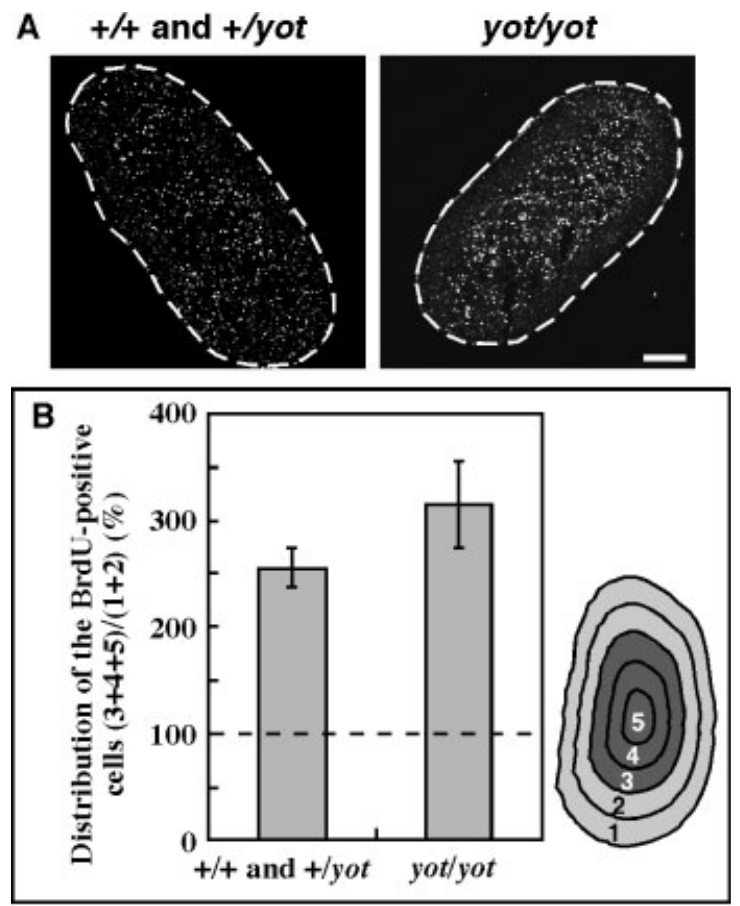

FIG. 8. Reelin signalling was not essential for birth-date-dependent cell segregation in culture.The E16 VZ and IMZ cells of homozygous yotari mice (yot/yot) or their littermates $(+/+$ and $+/$ yot $)$ labelled with BrdU at E14 were rotation-cultured for 3 days ( 5 r.p.m.). (A) Cryosections of the aggregates were stained with anti-BrdU antibody. (B) For statistical analysis, the fluorescence images of the aggregates were divided into five areas. Similarly to the wild-type cells, the E14-labelled cells from yot/yot mice tended to be located near the centre of the aggregates $(n=5)$. Scale bar, $100 \mu \mathrm{m}$.

E29-32 progenitors normally produce neurons destined for layers $\mathrm{V}$ and VI, whereas neurons of layers II and III are born on P0 or P1. If E29 cells in the $\mathrm{S}$ phase of the cell cycle were transplanted into P1 hosts, when examined several weeks later the E29 cells tended to have localized in layers II and III. By contrast, when E29 cells were transplanted into $\mathrm{P} 1$ hosts at a later stage of the cell cycle, they tended to localize in layer VI. These findings suggested that neurons generated early in cortical development become committed to their laminar position by environmental factors before their final mitotic division. On the other hand, when $\mathrm{P} 0$ progenitors were transplanted into E32 hosts, the progenitors were not competent to generate deep layer neurons and instead were restricted to producing only upper layer neurons, suggesting that the competence of progenitor cells to respond to the cues directing cells to align themselves in deep layers was lost during development (Frantz \& McConnell, 1996). Another experiment showed that the environmental cues were present in pellet cultures and explant cultures but not in low-density cultures, suggesting that the laminar fate of cortical neurons is determined by cell contact or short-range interactions in the VZ (Bohner et al., 1997). Gene expression studies have also shown that the transcription factor Otx1 is specifically expressed in deep-layer neurons from the time when they are progenitors in the VZ (Frantz et al., 1994a). The result of these studies suggested that ultimate laminar fate might at least to some extent be determined before neurons migrate before they reach the pial surface of the cortex. However, these transplantation studies did not address whether migration to beneath the $M Z$ is required for the ultimate localization of transplanted early-born cells to the deep layers, because the localization of transplanted cells was analysed several weeks after transplantation. Nor is it known how 'laminar fate' ultimately determines cell position. In the present study, we found that at least E14-labelled cells that were dissociated from the VZ and IMZ segregated from E13- or E15.5-labelled cells in aggregation cultures, suggesting that birth-date-dependent segregation properties were acquired before their migration to beneath the MZ. Moreover, E14labelled neurons dissociated from E14.5 VZ and IMZ localized near the centre of the aggregates in the long-term aggregation assay, even though they were mainly located in the $\mathrm{VZ}$ in vivo at the time of dissociation (Fig. 7D, H and I). Thus, the birth-date-dependent segregation properties of E14-labelled cells may be determined in the VZ rather than in the IMZ. As described previously (Takahashi et al., 1999), the majority of the layer IV neurons in the lateral cortex are born at E14 and the neurons in the adjacent layers are born at E13 (mainly layers V and VI) and E15.5 (mainly layers II and III). Thus, birth-date-dependent cell segregation mechanisms may contribute to the segregation of layer IV neurons from adjacent layer neurons. Indeed, the boundaries between layer IV and the adjacent layers (layers II and III and layer V) are prominent in the cerebral cortex (Nieuwenhuys, 1998).

Reelin, which is secreted by Cajal-Retzius neurons in the MZ (D'Arcangelo et al., 1995; Ogawa et al., 1995; Nakajima et al., 1997) and controls neuronal positioning extracellularly, is one of the essential factors of neuronal layer formation. In reeler mice, the cortical neurons that in normal animals localize in each of the cortical layers, including future layer IV neurons, tend to become widely distributed, and the layers are not clearly discernible. Moreover, previous reaggregation culture studies have shown that the E12 or E18 cerebral cortical cells of reeler mice fail to align normally in the aggregates (DeLong \& Sidman, 1970; Hoffarth et al., 1995; Ogawa et al., 1995). By contrast, E14-labelled yotari VZ and IMZ cells, which are unable to transduce Reelin signals because of the Dab1 deficiency (Sheldon et al., 1997; Yoneshima et al., 1997; Kojima et al., 2000), localized near the centre of the aggregates, similar to the E14-labelled normal cells in this study. Thus, at least at E14, the birthdate-dependent segregation mechanism is independent of Reelin signalling. Several abnormalities, such as the oblique axon trajectory across the cortical plate and the inverted dendrites of pyramidal cells, have been described in reeler mice (Goffinet, 1980; Pinto Lord \& Caviness, 1979), and in utero electroporation studies recently showed that late-born neurons in reeler mice tend to stop migrating along the borders of the internal plexiform zone, which is an abnormal structure formed by accumulation of neuronal dendrites (Tabata \& Nakajima, 2002). The result of these studies suggested that birth-date-dependent cell segregation alone is insufficient for normal layer formation, and that it occurs as a result of a combination of mechanisms in the developing cerebral cortex that includes Reelin signalling.

To characterize the 'segregation properties' of cortical neurons, we used two types of aggregation assays in this study. First, the short-term aggregation assay revealed that the E16 IMZ cells tended to adhere to each other in a $\mathrm{Ca}^{2+}$-dependent manner. The candidates for the molecules responsible for this adhesion include cadherins and C-type lectins, and several molecules that are important for brain development in these families have been reported so far. For example, N-cadherin is regulated by $\mathrm{Cdk} 5 / \mathrm{p} 35$, which is an essential complex for layer formation (Kwon et al., 2000). The selectin ligand CD15 has been reported to be a candidate molecule responsible for segregation of cortical neurons from striatal neurons (Gotz et al., 1996), and MNcadherin has been shown to regulate the segregation of motor pools during spinal cord development (Price et al., 2002). However, no cadherins or C-type lectins that are more highly expressed in the IMZ than in the VZ and CP are known. Additional studies are needed to identify the molecular basis of the $\mathrm{Ca}^{2+}$-dependent adhesion among IMZ cells. A second type of aggregation assay, the long-term 
aggregation assay, in this study revealed that E14-labelled neurons, many of which were located in the IMZ at E16, segregated from E13and E15.5-labelled neurons. In contrast to the short-term aggregation assay, which is thought to be based on signalling from the cell surface molecules, the long-term aggregation assay may be affected by cell divisions, migration and differentiation, in addition to the physicochemical properties of the cell surface molecules. In the retinal longterm reaagregation assay, a correct laminate structure was induced in the presence of pigment cells or Wingless-related MMTV integration site (Wnt) signalling (Fujisawa, 1971; Layer \& Willbold, 1989; Nakagawa et al., 2003). However, the addition of a soluble form of Wnt receptor in E16 VZ and IMZ aggregates did not change the birthdata-dependent segregation property (data not shown), suggesting the importance of other signalling cascades in this segregation. It is also important to determine the role of cell migration during cell sorting, especially because $\mathrm{N}$-cadherin is known to affect cell motility (Wheelock \& Johnson, 2003). However, for technical reasons we could not directly address the effect of cell migration using migrationblocking agents without interfering with cell adhesion, due to the long duration of culture in this study.

We detected nestin-positive fibers in the aggregates (Fig. $2 \mathrm{~K}$ and L), and found that spherical aggregates were not formed after long-term culture when the culture was conducted without VZ cells (data not shown). These results suggest the possibility that the nestin-positive radial glial cells in the VZ may be important for the aggregate formation. This may be a reasonable proposition because the locomotion neurons are known to migrate along the radial fibers in vivo. Recently, SPARC (secreted protein acidic and rich in cysteine)-like 1, which is localized on radial glial fibers, was identified as being an essential molecule for neuronal migration. It was reported that the expression of the molecule reduced the adhesivity of the neurons (Gongidi et al., 2004). SPARC-like 1 is one of the candidate molecules thought to be essential for the formation of spherical aggregates and birth-date-dependent cellular segregation. In addition to the abovementioned molecules, ephrin-Eph and semaphorin-neuropilin signalling, which regulates repulsive signalling, and integrins, which regulate the interaction between the migrating cells and the radial glial fibers (Anton et al., 1999), may also be responsible for the birth-datedependent segregation. The previous reaggregation culture study of the cerebral cortical cells also revealed that early, but not late, postmitotic neurons had selective adhesion properties (Krushel \& van der Kooy, 1993). However, they did not address the question of whether or not the cells in adjacent layers had differential segregation properties. In the present study, we dissected out the VZ and IMZ cells of the E16 cerebral cortex and found that the E14-labelled future layer IV cells were segregated from the E15.5-labelled layers II and III cells. Furthermore, we dissected out the VZ and IMZ cells of the E14.5 cerebral cortex and found that the E14-labelled future layer IV cells were segregated from the E13-labelled future layers V and VI cells. Thus, at least the future layer IV cells have the characteristics of being, or are potentially destined to be, segregated from the adjacent layer cells even without their migration to beneath the MZ.

By contrast, when the E16 VZ cells were mixed with E14 VZ cells, instead of E16 IMZ cells, and cocultured in the long-term aggregation system, E14-born cells were found to be distributed uniformly throughout the aggregates (data not shown), suggesting the importance of the presence of IMZ cells for the cellular alignment near the centre of the aggregates. Some extrinsic signals from IMZ cells may be required for the expression of the selective segregation properties. Due to technical difficulties, we were unable to investigate whether E14born E14.5 VZ cells and E14-born E16 IMZ cells would have differential or common segregation properties. Therefore, at present, we cannot rule out the possibility of maturity-dependent changes of the segregation properties.

How could the birth-date-dependent segregation properties contribute to the segregation into layers? At first, future layer IV neurons accumulated in the IMZ (Fig. 1A) and then passed the early-born CP cells (Fig. 1A and C). Although they appear to migrate as individual cells through the CP (Fig. 1A and C; arrowheads), they assembled again with each other beneath the MZ (Fig. 1C); this occurred a few days after they left the VZ. If the cultured cells in the aggregates after long-term culture acquire the properties shared by the cells that reach beneath the $\mathrm{MZ}$ in vivo, the birth-date-dependent segregation properties may contribute to the formation of layers in a birth-date-dependent manner. Future studies will be needed to demonstrate a direct relationship between the mechanism of this segregation and the final positioning of cortical neurons in their respective layers in the cortex.

\section{Acknowledgements}

We thank T. Sato, A. Kanai and S. Matsuo for technical assistance, members of Nakajima laboratory for valuable discussion, and J. Miyazaki for the pCAGGSEGFP plasmid vector. The mouse anti-Otx1 antibody was obtained from Developmental Studies Hybridoma Bank. This work was supported by grants from Japan Science and Technology Corporation, Ministry of Education, Culture, Sports, and Science and Technology of Japan, Japan Society for the Promotion of Science (JSPS), Keio University Special Grant-in-Aid for Innovative Collaborative Research Projects, the Ichiro Kanehara Foundation, the Casio Science Promotion Foundation, the Sumitomo Foundation, Novartis Foundation, Japan Brain Foundation, and the Terumo Lifescience Foundation. I.A. was a postdoctoral research fellow of JSPS.

\section{Abbreviations}

BrdU, 5'-bromodeoxyuridine; CAG, chicken $\beta$-actin promoter and cytomegalovirus enhancer; CP, cortical plate; Dab1, Disabled homologue 1; div, days in vitro; DMEM-F12, Dulbecco's modified Eagle's medium with nutrient mixture F-12; E, embryonic day; EDTA, ethylenediamine tetraacetic acid; EGFP, enhanced green fluorescent protein; GFAP, glial fibrillary acidic protein; hiv, hours in vitro; IMZ, intermediate zone; MAP2, microtubule-associated protein 2; MZ, marginal zone; P, postnatal day; PBS, phosphate-buffered saline; PCNA, proliferating cell nuclear antigen; SVZ, subventricular zone; TuJ1, $\beta$ IIItubulin; VZ, ventricular zone.

\section{References}

Anderson, S.A., Eisenstat, D.D., Shi, L. \& Rubenstein, J.L. (1997) Interneuron migration from basal forebrain to neocortex: dependence on Dlx genes. Science, 278, 474-476.

Angevine, J.B. \& Sidman, R.L. (1962) Autoradiographic study of cell migration during histogenesis of cerebral cortex in the mouse. Nature, 192, 766-768.

Anton, E.S., Kreidberg, J.A. \& Rakic, P. (1999) Distinct functions of alpha3 and alpha (v) integrin receptors in neuronal migration and laminar organization of the cerebral cortex. Neuron, 22, 277-289.

Bohner, A.P., Akers, R.M. \& McConnell, S.K. (1997) Induction of deep layer cortical neurons in vitro. Development, 124, 915-923.

Caviness, V.S. Jr \& Sidman, R.L. (1973) Time of origin or corresponding cell classes in the cerebral cortex of normal and reeler mutant mice: an autoradiographic analysis. J. Comp. Neurol., 148, 141-151.

D’Arcangelo, G., Miao, G.G., Chen, S.C., Soares, H.D., Morgan, J.I. \& Curran, T. (1995) A protein related to extracellular matrix proteins deleted in the mouse mutant reeler. Nature, 374, 719-723.

DeLong, G.R. (1970) Histogenesis of fetal mouse isocortex and hippocampus in reaggregating cell cultures. Dev. Biol., 22, 563-583.

DeLong, G.R. \& Sidman, R.L. (1970) Alignment defect of reaggregating cells in cultures of developing brains of reeler mutant mice. Dev. Biol., 22, 584-600.

Falconer, D.S. (1951) Two new mutants trembler and reeler, with neurological actions in the house mouse. J. Genet., 50, 192-201.

Frantz, G.D., Bohner, A.P., Akers, R.M. \& McConnell, S.K. (1994a) Regulation of the POU domain gene SCIP during cerebral cortical development. J. Neurosci., 14, 472-485. 
Frantz, G.D., Weimann, J.M., Levin, M.E. \& McConnell, S.K. (1994b) Otx1 and Otx2 define layers and regions in developing cerebral cortex and cerebellum. J. Neurosci., 14, 5725-5740.

Frantz, G.D. \& McConnell, S.K. (1996) Restriction of late cerebral cortical progenitors to an upper-layer fate. Neuron, 17, 55-61.

Fujisawa, H. (1971) A complete reconstruction of the neural retina of chick embryo grafted onto the chorio-allantoic membrane. Dev. Growth Differ., 13, 25-36.

Garber, B.B., Huttenlocher, P.R. \& Larramendi, L.H. (1980) Self-assembly of cortical plate cells in vitro within embryonic mouse cerebral aggregates. Golgi and electron microscopic analysis. Brain Res., 201, 255-278.

Goffinet, A.M. (1980) The cerebral cortex of the reeler mouse embryo. An electron microscopic analysis. Anat Embryol., 159, 199-210.

Gongidi, V., Ring, C., Moody, M., Brekken, R., Sage, E.H., Rakic, P. \& Anton, E.S. (2004) SPARC-like 1 regulates the terminal phase of radial glia-guided migration in the cerebral cortex. Neuron, 41, 57-69.

Gotz, M., Wizenmann, A., Reinhardt, S., Lumsden, A. \& Price, J. (1996) Selective adhesion of cells from different telencephalic regions. Neuron, 16, 551-564.

Hatten, M.E. \& Francois, A.M. (1981) Adhesive specificity of developing cerebellar cells on lectin substrata. Dev. Biol., 87, 102-113.

Hirotsune, S., Takahara, T., Sasaki, N., Hirose, K., Yoshiki, A., Ohashi, T., Kusakabe, M., Murakami, Y., Muramatsu, M., Watanabe, S.\& et al. (1995) The reeler gene encodes a protein with an EGF-like motif expressed by pioneer neurons. Nat. Genet, 10, 77-83.

Hoffarth, R.M., Johnston, J.G., Krushel, L.A. \& van der Kooy, D. (1995) The mouse mutation reeler causes increased adhesion within a subpopulation of early postmitotic cortical neurons. J. Neurosci., 15, 4838-4850.

Kojima, T., Nakajima, K. \& Mikoshiba, K. (2000) The disabled 1 gene is disrupted by a replacement with L1 fragment in yotari mice. Brain Res. Mol. Brain Res., 75, 121-127.

Krushel, L.A. \& van der Kooy, D. (1993) Pattern formation in the developing mammalian forebrain: selective adhesion of early but not late postmitotic cortical and striatal neurons within forebrain reaggregate cultures. Dev. Biol., 158, 145-162.

Kudo, C., Ajioka, I., Hirata, Y. \& Nakajima, K. (2005) Expression profiles of EphA3 at both the RNA and protein level in the developing mammalian forebrain. J. Comp. Neurol., 487, 255-269.

Kwon, Y.T., Gupta, A., Zhou, Y., Nikolic, M. \& Tsai, L.H. (2000) Regulation of N-cadherin-mediated adhesion by the p35-Cdk5 kinase. Curr. Biol., 10, 363-372.

Layer, P.G. \& Willbold, E. (1989) Embryonic chicken retinal cells can regenerate all cell layers in vitro, but ciliary pigmented cells induce their correct polarity. Cell Tissue Res., 258, 233-242.

Matsunami, H. \& Takeichi, M. (1995) Fetal brain subdivisions defined by R- and E-cadherin expressions: evidence for the role of cadherin activity in region-specific, cell-cell adhesion. Dev. Biol., 172, 466-478.

McConnell, S.K. \& Kaznowski, C.E. (1991) Cell cycle dependence of laminar determination in developing neocortex. Science, 254, 282-285.

Moscona, A. (1961) Rotation-mediated histogenetic aggregation of dissociated cells. A quantifiable approach to cell interactions in vitro. Exp. Cell Res., 22, 455-475.

Nakagawa, S., Takada, S., Takada, R. \& Takeichi, M. (2003) Identification of the laminar-inducing factor: Wnt-signal from the anterior rim induces correct laminar formation of the neural retina in vitro. Dev. Biol., 260, 414-425.

Nakajima, K., Mikoshiba, K., Miyata, T., Kudo, C. \& Ogawa, M. (1997) Disruption of hippocampal development in vivo by CR-50 mAb against reelin. Proc. Natl Acad. Sci. USA, 94, 8196-8201.

Nieuwenhuys, R. (1998) Structure and Organization of Centres. Springer, Heidelberg.

Ogawa, M., Miyata, T., Nakajima, K., Yagyu, K., Seike, M., Ikenaka, K., Yamamoto, H. \& Mikoshiba, K. (1995) The reeler gene-associated antigen on Cajal-Retzius neurons is a crucial molecule for laminar organization of cortical neurons. Neuron, 14, 899-912.
Park, H.T., Kim, Y.J., Yoon, S., Kim, J.B. \& Kim, J.J. (1997) Distributional characteristics of the mRNA for retinoid Z receptor beta (RZR beta), a putative nuclear melatonin receptor, in the rat brain and spinal cord. Brain Res., 747, 332-337.

Pinto Lord, M.C. \& Caviness, V.S. Jr (1979) Determinants of cell shape and orientation: a comparative Golgi analysis of cell-axon interrelationships in the developing neocortex of normal and reeler mice. J. Comp. Neurol., 187, 49-69.

Price, S.R., De Marco Garcia, N.V., Ranscht, B. \& Jessell, T.M. (2002) Regulation of motor neuron pool sorting by differential expression of type II cadherins. Cell, 109, 205-216.

Privat, A. (1975) Postnatal gliogenesis in the mammalian brain. Int. Rev. Cytol., 40, 281-323.

Sheldon, M., Rice, D.S., D’Arcangelo, G., Yoneshima, H., Nakajima, K., Mikoshiba, K., Howell, B.W., Cooper, J.A., Goldowitz, D. \& Curran, T. (1997) Scrambler and yotari disrupt the disabled gene and produce a reelerlike phenotype in mice. Nature, 389, 730-733.

Steinberg, M.S. (1970) Does differential adhesion govern self-assembly processes in histogenesis? Equilibrium configurations and the emergence of a hierarchy among populations of embryonic cells. J. Exp. Zool., 173, 395433.

Steinberg, M.S. \& Takeichi, M. (1994) Experimental specification of cell sorting, tissue spreading, and specific spatial patterning by quantitative differences in cadherin expression. Proc. Natl Acad. Sci. USA, 91, 206-209.

Tabata, H. \& Nakajima, K. (2001) Efficient in utero gene transfer system to the developing mouse brain using electroporation: visualization of neuronal migration in the developing cortex. Neuroscience, 103, 865-872.

Tabata, H. \& Nakajima, K. (2002) Neurons tend to stop migration and differentiate along the cortical internal plexiform zones in the Reelin signaldeficient mice. J. Neurosci. Res., 69, 723-730.

Tabata, H. \& Nakajima, K. (2003) Multipolar migration: the third mode of radial neuronal migration in the developing cerebral cortex. J. Neurosci., 23, 9996-10001.

Takahashi, T., Goto, T., Miyama, S., Nowakowski, R.S. \& Caviness, V.S. Jr (1999) Sequence of neuron origin and neocortical laminar fate: relation to cell cycle of origin in the developing murine cerebral wall. J. Neurosci., 19, 10357-10371.

Takahashi, T., Nowakowski, R.S. \& Caviness, V.S. Jr (1996) The leaving or Q fraction of the murine cerebral proliferative epithelium: a general model of neocortical neuronogenesis. J. Neurosci., 16, 6183-6196.

Takeichi, M. (1977) Functional correlation between cell adhesive properties and some cell surface proteins. J. Cell Biol., 75, 464-474.

Tarabykin, V., Stoykova, A., Usman, N. \& Gruss, P. (2001) Cortical upper layer neurons derive from the subventricular zone as indicated by Svet1 gene expression. Development, 128, 1983-1993.

Townes, P. \& Holtfreter, J. (1955) Directed movement and selectice adhesion of embryonic amphibian cells. J. Exp. Zool., 128, 53-120.

Weimann, J.M., Zhang, Y.A., Levin, M.E., Devine, W.P., Brulet, P. \& McConnell, S.K. (1999) Cortical neurons require Otx1 for the refinement of exuberant axonal projections to subcortical targets. Neuron, 24, 819-831.

Wheelock, M.J. \& Johnson, K.R. (2003) Cadherins as modulators of cellular phenotype. Annu. Rev. Cell Dev. Biol., 19, 207-235.

Whitesides, J.G. \& 3rd \& LaMantia, A.S. (1995) Distinct adhesive behaviors of neurons and neural precursor cells during regional differentiation in the mammalian forebrain. Dev. Biol., 169, 229-241.

Willbold, E., Reinicke, M., Lance-Jones, C., Lagenaur, C., Lemmon, V. \& Layer, P.G. (1995) Muller glia stabilizes cell columns during retinal development: lateral cell migration but not neuropil growth is inhibited in mixed chick-quail retinospheroids. Eur. J. Neurosci., 7, 2277-2284.

Yoneshima, H., Nagata, E., Matsumoto, M., Yamada, M., Nakajima, K., Miyata, T., Ogawa, M. \& Mikoshiba, K. (1997) A novel neurological mutant mouse, yotari, which exhibits reeler-like phenotype but expresses CR-50 antigen/reelin. Neurosci. Res., 29, 217-223. 